\title{
Examen Médico Nacional y Educación Médica en Chile
}

\author{
RICARDO ESPINOZA G. ${ }^{1}$ \\ 1. Decano, Facultad de Medicina, Universidad de Los Andes.
}

Los médicos sabemos muy bien que a un examen no se le puede exigir que mida más de aquello que para lo que fue creado. Con esa observación nos podemos situar frente al Examen Médico Nacional (EMN), valorarlo y dimensionar su aporte en la educación médica actual.

A comienzos del 2000, las facultades de medicina que constituían ASOFAMECH daban paulatino desarrollo a la implementación de un examen final común, para ser rendido por todos los egresados de la carrera de medicina. Fue diseñado como un examen que midiera conocimientos y destrezas intelectuales, en base a 180 preguntas que abarcasen las áreas de medicina interna y especialidades derivadas, pediatría, cirugía, obstetricia y ginecología, salud pública, psiquiatría y en menor proporción especialidades como oftalmología, dermatología y otorrinolaringología. Todas las preguntas debían ser aportadas por las facultades asociadas y evaluadas por sus representantes, para su validación desde el punto de vista técnico en cuanto a su confección y del contenido, de acuerdo a su atingencia. En diciembre de 2007 el EMN fue rendido por casi novecientos médicos recién titulados, provenientes de trece facultades de medicina, que constituyen prácticamente la mitad de las facultades que están en funcionamiento en la actualidad.

El EMN surgió como una necesidad de tener una observación objetiva de los conoci- mientos teóricos de los egresados, al momento de la titulación profesional. No puede ni debe constituirse como una prueba que valide el ejercicio profesional, colocando un rendimiento mínimo en conocimientos teóricos como única condición para poder ejercer la profesión en el país. Por un lado, fue la respuesta frente a la aparición de variadas escuelas de medicina, con orientaciones diferentes en cuanto a sus énfasis y perfiles de egreso, de modo de propender a que los conocimientos más propios e irrenunciables de la carrera fuesen entregados uniformemente y por tanto mensurables en cada médico; y por otro se planteó como una medida tendiente a asegurar la calidad de la educación médica. De esa forma, el EMN es también un elemento que permite dar confianza ante la opinión pública, puesto que se trasforma en la medida con la que los egresados de una escuela de medicina cumple con los objetivos acordados al momento de definirse un perfil. Hasta aquí las cosas, es bastante claro lo esperable del EMN y el desarrollo que ha tenido merece una entusiasta mirada.

Sin embargo, en la formación médica entran en escena otros elementos que una prueba como el EMN, al menos como está estructurada actualmente, no considera. En primer lugar están las habilidades prácticas que en mayor o menor medida son deseables al momento de titularse, y que ese novel médico podrá desa-

Correspondencia a:

Ricardo Espinoza G.

E-mail: respinoza@uandes.cl 
rrollar con mayor o menor destreza, seguridad, elegancia y efectividad. Pero sería sesgada la valoración del EMN si, por no incluir estos otros elementos, no apreciáramos su aporte. Un segundo ámbito que el EMN no considera, porque no ha sido diseñado para ello, es la evaluación de las actitudes y valoración moral que tienen los egresados sobre situaciones concretas y que reflejen su posición frente al dolor, la enfermedad, el inicio de la vida y su término, entre muchas otras. Prudentemente, y si bien esas posturas pueden ser compartidas por todas las facultades miembros de ASOFAMECH, la Asociación no las incluye en el examen y recaen en la misión de cada centro formador.

Por tanto, nos quedamos con un EMN que sólo mide una parte de la formación médica, no por omisión, sino porque deliberadamente ha sido concebido así. No obstante, todos estamos conscientes en que esos otros elementos, no evaluados, descansa una parte muy importante del universo de características que configuran a un buen médico. El desarrollo de un examen de este tipo pudiera incorporar, en un futuro, la medición de pruebas estandarizadas de competencias. Este es un objetivo con muchas dificultades para su implementación y elevados costos. Entonces, hoy, el EMN debe, necesariamente, valorarse y colocarse en el contexto para el que fue diseñado y con las limitaciones que se han expuesto. Pero, insistimos, no por sus limitaciones desconocemos su valor.

El aporte a la educación médica nacional de este examen viene por lograr que las facultades miembros de ASOFAMECH hayan acordado un perfil de egreso común para los médicos que hoy se titulan, acorde al estado del arte y, de este modo, permitir que cada facultad vaya monitorizando, con la observación de su tendencia en el tiempo, el grado de cumplimiento de sus egresados y del comportamiento de las distintas especialidades representadas en el referido examen, del perfil trazado. Es un destacado logro, que se hace exigible directamente a las facultades miembros de la asociación, pero secundariamente también exigible a los egresados de cualquier origen que desean continuar sus estudios de especialización en alguna facultad que forme parte de ASOFAMECH. Todas las escuelas de postgrado de las facultades asociadas han incorporado el puntaje individual obtenido en el EMN por cada postulante, como otro elemento discriminador en los concursos de especialización médica.

Tal como se ha repetido en distintas ocasiones, el EMN no está diseñado ni guarda entre sus objetivos crear un ordenamiento de calidad de las facultades de medicina, toda vez que su mirada y evaluación se hace sobre un universo incompleto. No fue pensado para que desembocara en un ranking, pero la realidad supera a la planificación y se quiera aceptar ó no, ese ordenamiento está en el ambiente y los resultados del EMN se leen como un ranking. Además, está el acuerdo tomado en el seno de ASOFAMECH dando beneplácito para que cada Facultad prepare a la promoción que rendirá el examen, del modo más prudente que estime. Por tanto, insisto en que se produce, quiérase o no, una competencia por obtener como Facultad, los mejores resultados. En este mismo sentido lo importante, más que tener un muy alto rendimiento ocasional, es mostrar una tendencia en los resultados y, que a través del tiempo, cada Facultad muestre un rendimiento en ascenso; que no tenga grandes fluctuaciones año a año. De ese modo, los resultados representan un trabajo sostenido y coherente.

Si observamos lo sucedido en últimos cuatro años en que se ha rendido oficialmente el EMN (período 2004-2007), son tres las facultades que, invariablemente, han demostrado en forma sostenida un alto rendimiento, representando los mejores promedios como escuela: Facultad de Medicina de la P. Universidad Católica de Chile, Facultad de Medicina de la Universidad de los Andes y Facultad de Medicina de la Universidad de Chile. En forma más afinada aún, podemos decir que en esos mismos años, la mitad o más de los egresados de esas escuelas se encontraba en los dos quintiles superiores de rendimiento. En cambio, al analizar la distribución se ha observado, también, que en otras escuelas los alumnos que ocupan el quintil superior no alcanza el $10 \%$.

De este efecto ranking inmediatamente surgen dos consecuencias. Una de ellas, de efectos potencialmente negativos, es que cada facultad participante viendo en su posición relativa a las demás, un efecto de imagen, dirija una 
parte importante de su dedicación docente a "obtener" alumnos que rindan un buen EMN, descuidando los otros aspectos formativos, previamente referidos, que son igualmente importantes. En ese mismo sentido es que por satisfacer el perfil de egreso, se vuelquen esfuerzos a que se cumplan sólo esos requisitos mínimos y no se disponga del tiempo y oportunidad para reforzar otros, universalmente importantes o que al menos sean destacados para una facultad en particular. En ese sentido debemos esforzarnos por los máximos, abriendo siempre fronteras que mejoren la formación de los estudiantes de medicina. No podemos conformarnos colocando mínimos que se transformen luego en las metas que cumplir.

$\mathrm{Y}$ en segundo lugar, y casi derivado de lo anterior, es que se disocie la correlación entre la Calificación Médica Nacional, nota al egreso que debiera representar el trabajo de todos los años de carrera, y el puntaje obtenido en el EMN. Es decir, un falsamente elevado puntaje en el EMN, producto de la preparación del examen. Más, lo que se ha observado, es una tendencia, sin que existan estudios estadísticos, es que en ciertas facultades los alumnos egresan con una alta Calificación y un relativo bajo rendimiento en el EMN. Pues bien, si el EMN mide conocimientos acordados, de modo uniforme, pareciera ser un indicador más fiel de éstos y mejor elemento de comparación, que un promedio de notas aplicadas con distinto rigor y por tanto, subidas en la escala. Ello, porque, los conocimientos que deben adquirirse en forma paulatina en el transcurso de la carrera, no pueden ser incorporados en forma súbita en los días finales antes de egresar. Sólo así se explica que alumnos provenientes de algunas facultades, con relativas buenas notas, obtengan una relativamente baja puntuación en el EMN.

A estas alturas ya habrán notado la similitud de esta situación de los egresados de medicina, con lo que sucede con los alumnos de enseñanza secundaria, sus notas y la Prueba de Selección Universitaria (PSU). También en este caso están surgiendo tendencias a observar que no siempre se correlacionan ambas mediciones, sólo que a la hora de considerar el caso individual, con puntuaciones no acordes, en esta situación sería más confiable el valor del EMN, puesto que las notas pueden provenir de una escala potenciada, de una facultad en particular.

Si continuamos con el análisis de los resultados, es esperable que si el EMN sólo mide conocimientos teóricos, y por tanto, elementos cognitivos, sean los alumnos con los mejores indicadores de ingreso a la Universidad, los que obtengan la mayor puntuación. Eso no se ha venido observando, puesto que existen facultades con alumnos de significativos mejores puntajes de ingreso, que no exhiben, como grupo, significativos mejores resultados. Esta observación admite varias explicaciones. Una de ellas, quizás la más obvia, sería que los criterios que determinan el puntaje de ingreso a la Universidad no reflejan, realmente, la potencia cognoscitiva de las personas. Una segunda lectura es que en los altos niveles en que se encuentra la mayoría de los alumnos que se matriculan en la carrera de medicina, no es posible segmentar categorías y los estudiantes son, en forma relativamente pareja, buenos alumnos. En cualquiera de estas situaciones, cabría volver a mirar cómo se selecciona el ingreso a la carrera. En cambio, si asumimos que los alumnos son significativamente diferentes al ingreso, pero al final de la carrera rinden de modo similar, lo que habría que mirar es cómo está haciendo su tarea cada facultad en particular. Dicho de otra forma, será, por tanto, tarea de cada Facultad, preocuparse por facilitar la expresión de todas las potencialidades de sus matriculados y hacer productivos los talentos que cada uno de ellos aporta, otorgando una dedicación y apoyo docente individual a cada estudiante, para que ello sea posible. Eso desde el punto de vista de las personas; si nos detenemos a comparar recursos y rendimiento, el que existan resultados similares con recursos diferentes puede significar que la dedicación al pregrado que haga cada Facultad, y su efectividad, sea relativamente mayor en algunas en relación con otras.

En la altura de desarrollo en que se encuentra el Examen Médico Nacional faltan muchas etapas por cumplir. Algunas de ellas las ha detectado la misma Asociación de Facultades y se encuentra dando pasos para su implementación. Por cierto que faltan estudios de valida- 
ción del examen, como también los diversos estudios de correlación de los resultados con variables como las sugeridos: puntajes de ingreso a la Universidad, proporción entre alumnos por docente, infraestructura y recursos de biblioteca, por nombrar sólo algunos. Sólo en la medida que esas asociaciones se conozcan y evalúen, podremos, con más propiedad dar el justo valor a este examen. Sólo así se podrá conocer al interior de cada Facultad de su eficiencia como centro formador y de cómo están siendo aprovechados los recursos.

En relación con otros aspectos relacionados también queda mucho desarrollo por lograr y aspectos por definir. Por ejemplo, la condición de los médicos extranjeros frente al EMN; su utilización como criterio de contratación por las instituciones de salud; y por cierto, su utilización como medida de validación para el ejercicio profesional, criterio este último que no ha encontrado eco en la Asociación, pues no ha sido ideado ni diseñado con este fin. Creemos que las razones analizadas explican esta posición.

No nos queda más que mirar el EMN con prudencia. No vaya a ser que los resultados iniciales enceguezcan a sus participantes y el sesgo producido impida mirar en forma integradora el conjunto de elementos que conforman una educación médica de calidad. Es del mayor interés que el EMN represente, efectivamente, una medida válida de rendimiento ante las mismas facultades de medicina, empleadores y público en general. Todos deseamos que el EMN se prestigie y su significado sea inobjetable por quienes lo rinden y por las mismas instituciones universitarias que lo avalan. 